thyrotoxicosis, two thirds of the affected sibling pairs shared both parental haplotypes. It was postulated that both parental haplotypes were important for the development of thyrotoxicosis. In other words the human leucocyte antigen gene contributing to the development of thyrotoxicosis may be inherited in a recessive fashion.'

Separate alleles (Bw22 and B17) have been suggested as markers for thyrotoxic periodic paralysis. It remains unclear whether the mode of inheritance of thyrotoxic periodic paralysis is similar to that of thyrotoxicosis per se. This family provided us with a unique opportunity to glimpse the genetic mechanisms occurring in thyrotoxic periodic paralysis. The occurrence of identical haplotypes in the sibling pair who had

\section{Notification of tuberculosis: Can the pathologist help?}

\section{B L Bradley, K M Kerr, A G Leitch, D Lamb}

Royal Victoria Dispensary for Diseases of the Chest, Edinburgh

B L Bradley, MRCP, registrar A G Leitch, $\mathrm{FRCP}$, consultant physician

Department of Pathology, University of Edinburgh K M Kerr, MB, senior registrar D Lamb, FRCPATH, reader

Correspondence to: $\mathrm{Dr}$ A G Leitch, Chest Unit, City Hospital, Edinburgh thyrotoxic periodic paralysis suggests that the mode of inheritance of thyrotoxic periodic paralysis and thyrotoxicosis may indeed be similar.

1 Mittal KK, Mickey MR, Singal DP, Terasaki PI. Serotyping for homotransplantation 18: refinement of microdroplet lymphocyte cytotoxicity test. Transplantation 1968;6:913-27.

2 Chan SH, Yeo PPB, Tan SH, Wee GB, Lui KF, Cheah JS. Bw46 and DRw9 associations in Singaporean Chinese Graves' disease. In: Aizawa M, ed. HLA in Asia-Oceania. Japan: Hokkaido University Press, 1986:771-3.

3 Yeo PPB, Chan SH, Lui KF, Wee GB, Lim P, Cheah JS. HLA and thyrotoxic periodic paralysis. Br Med $\mathcal{f} 1978$;ii:930.

4 Cheah JS. Thyrotoxic periodic paralysis in Singapore. In: Cheah JS, Lim P, Tambyah JA, et al, eds. Proceedings of the Sixth Asia and Oceania Congress of Endocrinologv, Singapore 1978;1:282-99.

5 Tian D, Mao TS, Yang SH, et al. HLA haplotypes sharing in multiple thyrotoxicosis families. In: Aizawa M, ed. HLA in Asia-Oceania. Japan: Hokkaido University Press, 1986:764-7.

(Accepted 21 April 1988)
The incidence of tuberculosis in Great Britain has declined steadily over recent decades, the trend being confirmed by statutory notification data. ' : In 1986 over 6000 cases of tuberculosis were notified but this figure may be too low, for ambiguities and inaccuracies are recognised to exist in the notification system in England and Wales. ${ }^{3}$ Data for the United States show that $37 \%$ of cases go unreported. ${ }^{+}$

For many years in Scotland it has been the practice to notify all positive bacteriological results to cover possible failures in notification by clinicians. We wondered whether a similar procedure of notification for positive pathological biopsy specimens would further improve notification practices. We have therefore identified pathological diagnoses of tuberculosis over four years, examined their characteristics, and related the findings to notification data.

\section{Methods and results}

All pathology reports issued from the University Department of Pathology, Edinburgh, in which tuberculosis was listed as the primary diagnosis or in the differential diagnosis were examined for the years 1981-4. The slides of all cases were reviewed. Patients' case notes were scrutinised for details of diagnosis, treatment, and whether a respiratory physician had been consulted. Cases were checked against the local tuberculosis register for the corresponding years to see whether they had been notified.

Pathology reports were coded as follows: (A) a firm pathological diagnosis of tuberculosis in which acid fast organisms were present in the sections; (B) strongly suggestive or firm diagnosis of tuberculosis made on morphological grounds, though acid fast bacilli were not seen; (C) cases in which a firm diagnosis of inactive, calcified, or healed tuberculosis was made; (D) cases in which tuberculosis was mentioned in the differential diagnosis for confirmation or exclusion on clinical grounds.

Eighty two sets of case notes and pathology reports were examined. Eight sets of case notes could not be traced. Thirty four cases were coded A, $35 \mathrm{~B}$, five C, and eight $\mathrm{D}$.

Codes $A$ and $B$-The table gives the age and sex characteristics of the 69 patients coded A or B by the pathologist together with information on the number of notifications and number of consultations with a respiratory physician. Of patients in whom acid fast bacilli were identified, $11(32 \cdot 4 \%)$ were not notified, and of those in whom acid fast bacilli were not seen but a firm pathological diagnosis was made, 15 (42.9\%) were not notified. Only eight of the 69 patients were not seen by a respiratory physician. One of the unnotified patients had acid fast bacilli in a sputum smear. Sixty two of the the 69 patients were treated for tuberculosis. Of these 62 patients treated, and therefore considered to have active disease, only two thirds were notified. In this group 50 patients $(81 \%)$ had chemotherapy for the standard six or nine months. Unusual treatment combinations, all based on rifampicin, were employed in 12 patients, on four occasions by chest physicians. Failure to notify was equally common in physicians and surgeons, though the comparatively larger number of pathological diagnoses on material obtained by surgeons $(48 v 21)$ led to a greater number of failed notifications.

Codes $C$ and $D$-None of the 13 patients coded $C$ or $\mathrm{D}$ was notified or treated as a case of tuberculosis.

Age and sex characteristics of patients coded $A$ or $B$ with details of number notified and number seen by respiratory physician

\begin{tabular}{llll}
\hline & Code A & Code B & Total \\
\hline Mean age in years (range) & $53(9-80)$ & $52(11-87)$ & $53(9-87)$ \\
No male & 21 & 16 & 37 \\
No female & 13 & 19 & 32 \\
No notified & 23 & 20 & 43 \\
No(\%) not notified & $11(32 \cdot 4)$ & $15(42 \cdot 9)$ & $26(37 \cdot 7)$ \\
No not seen by respiratory & & \multicolumn{2}{c}{} \\
$\quad$ physician & 4 & \multicolumn{2}{c}{8} \\
Notified & 2 & 1 & 3 \\
Not notified & 2 & 3 & 5 \\
\end{tabular}

\section{Comment}

This study shows that almost $40 \%$ of patients (26/69) with a convincing combined clinical and pathological diagnosis of tuberculosis were not notified, in keeping with findings in the United States. ${ }^{+}$Most failures of notification occurred in surgical wards, though physicians also failed to notify positive pathological diagnoses of tuberculosis. Fortunately, treatment was conventional in most cases and respiratory physicians were consulted in most. Our study suggests that all positive pathological diagnoses of tuberculosis should be notified to the local health board to ensure that notifications reflect the true incidence of disease. This would also ensure that appropriate contact procedures can be instituted.

1 MRC Tuberculosis and Chest Disease Unit. National survey of tuberculosi notifications in England and Wales 1978-9. Br Med J 1980;281:895-9.

2 MRC Tuberculosis and Chest Diseases Unit. National notifications of tuberculosis in England and Wales 1983. Br Med $\mathcal{J}$ 1985;291:658-61.

3 Davies PDO, Darbyshire J, Nunn AJ, el al. Ambiguitics and inaccuracies in the notification system for tuberculosis in England and Wales. Community Med 1981:3:108-18.

Marier R. The reporting of communicable diseases. Am 7 Epidemiol 1977; 105:587-90.

5 Capewell SC, Leitch AG. The value of contact procedures for tuberculosis in Edinburgh. Br f Dis Chest 1984;78:317-29.

(Accepted 10 Mav 1988) 